Research Article

\title{
Demographic Data for SCSP Mobile Health Care Programme Conducted in the Rural Area of Bhopal District, Madhya Pradesh
}

\author{
Amir Faisal Khan', Afshan Qaiser' ${ }^{2}$ Yasmin Fatima ${ }^{3}$ Abrar Mohd Khan ${ }^{4}$, Abdul Raheem ${ }^{5}$, \\ Tamanna Nazli ${ }^{6}, \underline{\text { Shagufta Parveen }}{ }^{7}$ \\ 1,2Research Officer, ${ }^{3,4}$ Research Associate (Unani), Clinical Research Unit Bhopal, Under CCRUM, Ministry of AYUSH Govt. of India. \\ ${ }^{5,6}$ Research Officer, ${ }^{7}$ Research Associate (Unani), Central Council for Research in Unani Medicine (CCRUM) Delhi, Ministry of \\ AYUSH Govt. of India.
}

DOI: https://doi.org/10.24321/2454.325X.202101

I $\quad \begin{array}{lll}\mathbf{N} & \mathbf{F} & \mathbf{O}\end{array}$

\section{Corresponding Author:}

Yasmin Fatima, Clinical Research Unit Bhopal, Under CCRUM, Ministry of AYUSH Govt. of India.

E-mail Id:

yas.fatima2014@gmail.com

Orcid Id:

https://orcid.org/0000-0003-3490-8802

How to cite this article:

Khan AF, Qaiser A, Fatima Y, Khan AM, Raheem A, Nazli T, Parveen S. Demographic Data for SCSP Mobile Health Care Programme Conducted in the Rural Area of Bhopal District, Madhya Pradesh. Int J Preven Curat Comm Med. 2021;7(1):4-10.

Date of Submission: 2021-03-02

Date of Acceptance: 2021-03-28

\section{$\begin{array}{llllllll}\mathbf{A} & \mathbf{B} & \mathbf{S} & \mathbf{T} & \mathbf{R} & \mathbf{A} & \mathbf{C} & \mathbf{T}\end{array}$}

Introduction: Demography is the statistical and mathematical study of the size composition and spatial distribution of human populations. In this article we focused on some demographic data such as age, gender, education, caste, religion, marital status, occupation, addiction and dietary habits which may help to assess the socio economic and health status of the population.

Methods: This is an observational and descriptive study, where data collected using a pretested, predesigned questionnaire/screening form to assess the demographic information i.e. age, gender, education, caste, religion, marital status, occupation, addiction and dietary habits, provided by Central Council for Research in Unani Medicine(CCRUM), Ministry of AYUSH, Govt. of India, Delhi. Sample size was not calculated as all the patients who were coming to OPD were included in the study and all patients were assured of confidentiality of the details collected and patients provided data willingly. Inclusion criteria for the study included all the patients of either sex of any age group attending OPDs in five adopted villages, i.e. Kurana, Kalkheda, Bagoniya, Toomda and Dhammarra during July 2019 to March 2020 at SCSP Mobile Healthcare Programme, Clinical Research Unit, Bhopal.

Results and Conclusion: Collected and compiled data exhibits that the Scheduled Castes population visited the OPDs belongs to a low socioeconomic group and are mainly small farmers and landless labourers. The percentage of the female population who visited the OPDs was more which reveals that due to the excessive burden of work and poor nutritional diet they are more susceptible to have an illness. Literacy level was fair among population with $19.16 \%$ illiterate. Tobacco chewing is seen more prevalent among the participants. Poverty and less availability of food have led to unsatisfactory dietary habit, though literacy is considerable in these villages.

Keywords: Demographic, SCSP, Ministry of AYUSH, CCRUM Scheduled Castes, Unani 


\section{Introduction}

Demography is the statistical and mathematical study of the size, composition, and spatial distribution of human populations. In this article we focus on some demographic data of age, gender, education, caste, religion, occupation, addiction and dietary habits which may help to assess the socio-economic and health status of the population. Collecting race and ethnicity data can help improve the quality of care for all patients because it helps to identify and address differences in care for specific populations and distinguish which populations do not achieve optimal interventions. Survey research is the most fundamental tool for all quantitative outcome research methodologies and studies. ${ }^{1}$

More formal definitions of demography say much the same thing in a bit more precise terms. Demography is the science of populations that examines the following:

1. The size and composition of populations according to different criteria: age, ethnicity, sex, marital status, educational attainment, spatial distribution, and so on.

2. Dynamic life-course processes that change this composition: birth, death, unions, migration, etc.

3. Population composition is the description of a population according to characteristics such as age and sex, and is a part of social environment, it provides a framework against which to interpret the health status and behaviours of the population. ${ }^{2}$

Socio-economic status is a combined economic and sociological measure of a person's work experience and the measure of an individual's or family's economic and social position in relation to others. When analysing a family's socioeconomic status, the household income, earners' education, and occupation are examined, along with the combined income, whereas, for an individual's socioeconomic status only their own attributes are assessed. However, Socio-economic status is more commonly used to depict an economic difference in society as a whole. ${ }^{3,4}$

Socio-economic status is typically broken into three levels (high, middle, and low) to describe the three places a family or an individual may fall into. When placing a family or individual into one of these categories, any or all of the three variables (income, education, and occupation) can be assessed.

Education also plays a role in income. Median earnings increase with each level of education. As conveyed in the chart, the highest degrees, professional and doctoral degrees, make the highest weekly earnings while those without a high school diploma earn less. Higher levels of education are associated with better economic and psychological outcomes (i.e., more income, more control, and greater social support and networking). ${ }^{3,5}$
Recently, there has been an increasing interest among epidemiologists on the subject of economic inequality and its relation to the public health. Socioeconomic status has long been related to health, those higher in the social hierarchy typically enjoy better health than those below. ${ }^{3,6,7}$

The Mobile Healthcare Programme under Schedule Caste Sub Plan was initiated in July 2019 under the direction of Central Council for Research in Unani Medicine, New Delhi.

The demographic data is obtained from SCSP Mobile Healthcare Programme Clinical Research Unit Bhopal under Ministry of AYUSH, Govt. of India.

\section{Methodology}

To execute this programme, 5 villages had been selected by the Clinical Research Unit Bhopal. Gram sarpanch/ gram secretary of selected areas were consulted before implementation of the Unani Mobile Healthcare Programme under the Scheduled Caste Sub Plan (SCSP).

To expand healthcare programme to a large number of populations, camps were organised at public places like gram panchayat office, anganwadi and schools etc. Door to door surveys were done to create awareness about the objectives of the programme and to provide healthcare services to the underprivileged population.

The main objective of the study is to analyse/ screen the health status of the scheduled caste population of rural Bhopal, Madhya Pradesh. This is an observational and descriptive study, where the data was collected using a pretested, predesigned questionnaire/ screening forms to assess the demographic information i.e. age, gender, education, caste, religion, marital status, occupation, addiction and dietary habits. Sample size was not calculated as all the patients who were coming to OPD were included in the study, and all patients were assured of confidentiality of the details collected and patients provided data willingly. All the patients of either sex of any age group attending OPDs in five adopted villages, i.e. Kurana, Kalkheda, Bagoniya, Toomda and Dhammarra during July 2019 to March 2020 at SCSP Mobile Healthcare Programme Clinical Research Unit Bhopal. Who gave consent for the study were included in the study. This is the Central Council for Research in Unani Medicine (CCRUM), Ministry of AYUSH, Govt. of India's approved programme running all over India in different centres for the benefit of SC and ST population with the view to assess their health status as well as to provide Unani treatment to the patients suffering from different ailments.

\section{Result and Discussion}

Data was obtained through the SCSP Mobile Healthcare OPDs conducted in five adopted villages by Clinical Research Unit, Bhopal under the Central Council for Unani Medicine (CCRUM), Ministry of AYUSH Govt. by India from 22 July 
2019 to 31 March 2020. Information regarding the age, gender, education, caste, religion, marital status, occupation, addiction and dietary habits and socio-economic status were collected from the total number of visits made in OPDs during the period of study in five adopted villages with the help of predesigned screening forms. Data were divided into different demographic categories in a tabulated form to make it easy to assess and understand.

Table 1 shows that the total percentage of males who visited OPDs in the adopted (Kurana, Kalkheda, Bagoniya, Toomda and Dhammarra) villages were $40.54 \%$, females who visited were $46.66 \%$ and children were $12.78 \%$. Data reveals that female patients were more in number as compared to the male patients.

Table 2, exhibits the total percentage of the participants as per their castes (scheduled caste, scheduled tribe and others). The percentage of scheduled caste males was $16.20 \%$, females constituted $19.36 \%$, and children constituted $5.13 \%$. The total percentage of SC population that visited the OPD was $40.69 \%$. SCSP mobile healthcare programme was the beneficiary for the schedule caste population and for the improvement of their health status.

The total percentage of the scheduled tribe population was $1.60 \%$ and the other population was $57.03 \%$.

Table I.Gender-wise Distribution of Population of the Five Villages of Bhopal district

\begin{tabular}{|c|c|c|c|c|c|c|}
\hline \multirow{2}{*}{ Village } & \multicolumn{2}{|c|}{ Male } & \multicolumn{2}{c|}{ Female } & \multicolumn{2}{c|}{ Children } \\
\cline { 2 - 7 } & Numbers & Percentage & Numbers & Percentage & Numbers & Percentage \\
\hline Kurana & 333 & 5.11 & 571 & 8.76 & 164 & 2.51 \\
\hline Kalkheda & 195 & 2.99 & 444 & 6.81 & 171 & 2.16 \\
\hline Bagoniya & 458 & 7.02 & 722 & 11.08 & 300 & 4.60 \\
\hline Toomda & 764 & 11.72 & 887 & 13.61 & 116 & 1.78 \\
\hline Dhammarra & 892 & 13.68 & 417 & 6.39 & 82 & 1.25 \\
\hline TOTAL & 2,642 & 40.54 & 3,041 & 46.66 & 833 & 12.78 \\
\hline
\end{tabular}

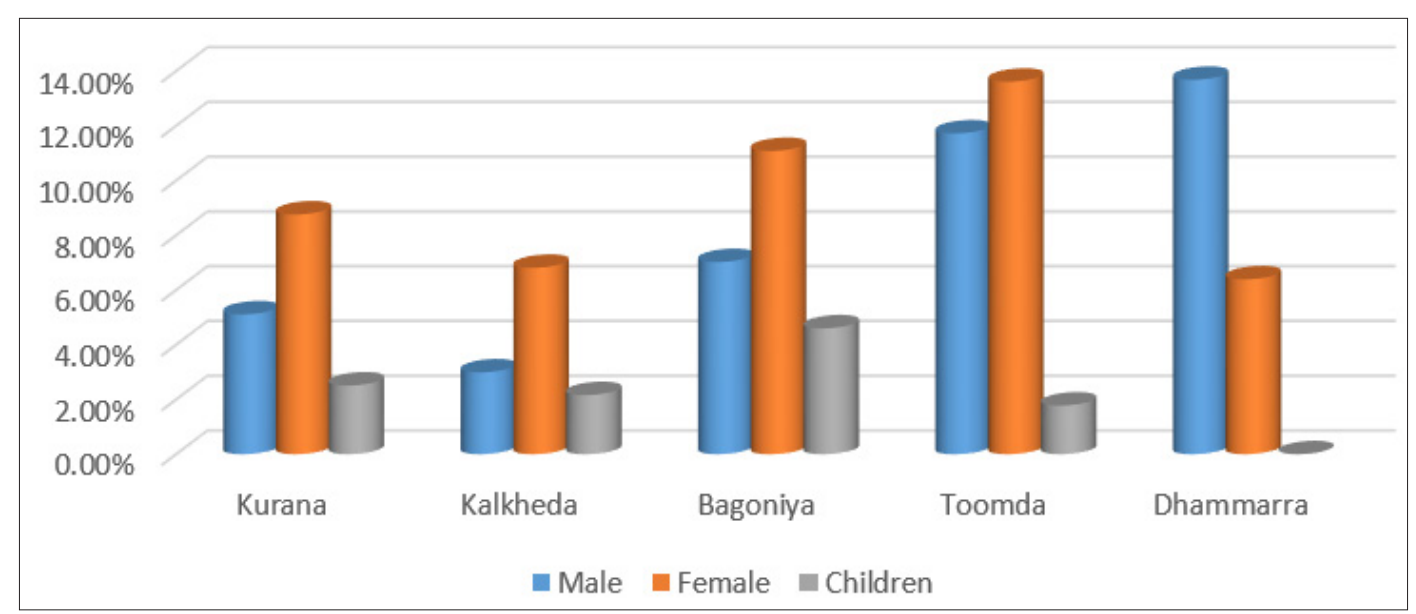

Figure I.Gender-wise Distribution of Population (\%)

Table 2.Caste-wise Distribution of Population of the Five Villages of Bhopal district

\begin{tabular}{|c|c|c|c|c|c|c|c|c|c|}
\hline \multirow{2}{*}{ Villages } & \multicolumn{3}{|c|}{ Scheduled Caste } & \multicolumn{3}{c|}{ Scheduled Tribe } & \multicolumn{3}{c|}{ Others } \\
\cline { 2 - 10 } & $\begin{array}{c}\text { Male } \\
\text { (\%) }\end{array}$ & $\begin{array}{c}\text { Female } \\
\text { (\%) }\end{array}$ & $\begin{array}{c}\text { Children } \\
(\%)\end{array}$ & $\begin{array}{c}\text { Male } \\
\text { (\%) }\end{array}$ & $\begin{array}{c}\text { Female } \\
(\%)\end{array}$ & $\begin{array}{c}\text { Children } \\
(\%)\end{array}$ & $\begin{array}{c}\text { Male } \\
\text { (\%) }\end{array}$ & $\begin{array}{c}\text { Female } \\
\text { (\%) }\end{array}$ & $\begin{array}{c}\text { Children } \\
\text { (\%) }\end{array}$ \\
\hline Kurana & 2.82 & 5.87 & 1.67 & 0.23 & 0.19 & 0.06 & 2.55 & 1.68 & 0.78 \\
\hline Kalkheda & 1.24 & 2.82 & 1.25 & 0.06 & 0.26 & 0.03 & 1.68 & 3.92 & 1.44 \\
\hline Bagoniya & 3.08 & 3.48 & 1.41 & 0 & 0 & 0 & 3.94 & 7.59 & 3.29 \\
\hline Toomda & 4.15 & 5.14 & 0.47 & 0.16 & 0.13 & 0.12 & 7.59 & 8.53 & 1.28 \\
\hline Dhammarra & 4.91 & 2.05 & 0.33 & 0.29 & 0.07 & 0 & 8.48 & 4.26 & 0.02 \\
\hline Total & 16.20 & 19.36 & 5.13 & 0.74 & 0.65 & 0.21 & 24.24 & 25.98 & 6.81 \\
\hline
\end{tabular}




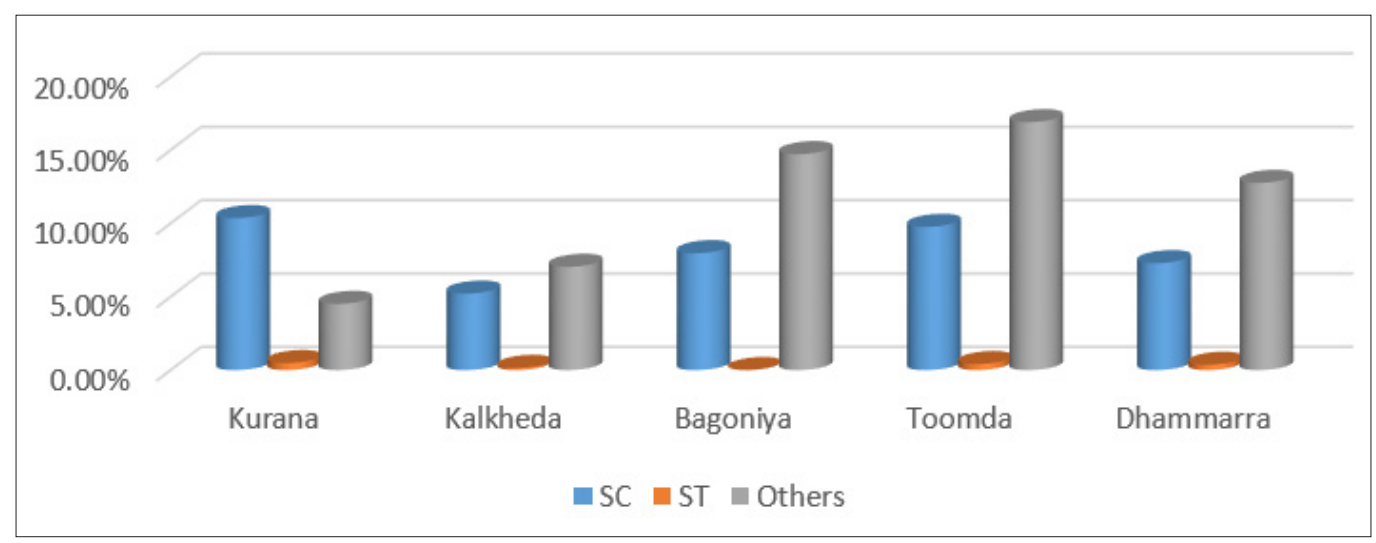

Figure 2.Caste-wise Distribution of Population (\%)

Table 3.Religion-wise Distribution of Population of the Five Villages of Bhopal district

\begin{tabular}{|c|c|c|c|c|c|c|}
\hline \multirow{2}{*}{ Village } & \multicolumn{2}{|c|}{ Hindu } & \multicolumn{2}{c|}{ Muslim } & \multicolumn{2}{c|}{ Christian } \\
\cline { 2 - 7 } & Number & Percentage & Number & Percentage & Number & Percentage \\
\hline Kurana & 1043 & 16.00 & 25 & 0.38 & 0 & 0.00 \\
\hline Kalkheda & 467 & 7.16 & 342 & 5.24 & 1 & 0.01 \\
\hline Bagoniya & 624 & 9.57 & 856 & 13.13 & 0 & 0.00 \\
\hline Toomda & 1645 & 25.24 & 122 & 1.87 & 0 & 0.00 \\
\hline Dhammarra & 1238 & 18.99 & 153 & 2.34 & 0 & 0.00 \\
\hline TOTAL & 5017 & 76.99 & 1498 & 22.98 & 1 & 0.01 \\
\hline
\end{tabular}

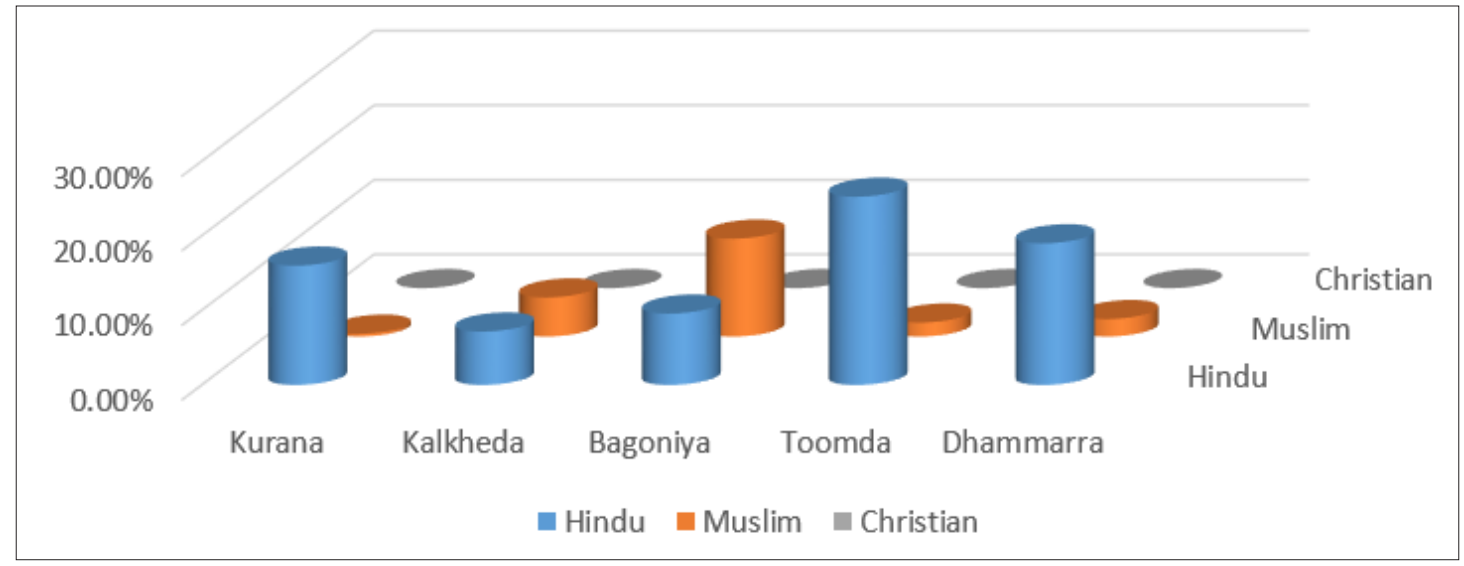

Figure 3.Religion-wise Distribution of Population (\%)

Table 3, reveals that from the total population that visited the SCSP OPD, 76.99\% belonged to the Hindu community and $22.98 \%$ belonged to the Muslim community. The percentage of people who belonged to the Christian community was negligible.

Table 4 , shows that $19.16 \%$ of the population was illiterate, $6.38 \%$ was semi-literate, $37.21 \%$ had studied up to 8 th class, $26.70 \%$ had studied up to high school, $9.11 \%$ of the population had studied up to higher secondary, and $1.41 \%$ were graduate and above. Data exhibits that only $19.16 \%$ of the population of these five villages was not literate, and $70-80 \%$ of the population could read and write.
As shown in the Table 5, 15.05\% of the population was not working, $14.47 \%$ were landholders, $6.52 \%$ were agricultural labourers, $10.68 \%$ were unskilled labourers, $1.47 \%$ were skilled labourers, $0.82 \%$ were doing business, $18.06 \%$ were students, and $32.90 \%$ females were housewives. Data show that more than $18 \%$ of the population belonged to labour class and had low socio-economic status.

Table 6 shows that about $71.76 \%$ of patients were taking vegetarian diet and $26.79 \%$ were taking non-vegetarian diet followed by $1.44 \%$ patients were taking vegetarian diet with egg. 
Table 4.Education-wise Distribution of Population of the Five Villages of Bhopal district

\begin{tabular}{|c|c|c|c|c|c|c|c|c|c|c|c|c|}
\hline \multirow{2}{*}{ Village } & \multicolumn{2}{|c|}{ Illiterate } & \multicolumn{2}{|c|}{ Semi-Literate } & \multicolumn{2}{|c|}{ Primary School } & \multicolumn{2}{|c|}{ High School } & \multicolumn{2}{|c|}{ Intermediate } & \multicolumn{2}{|c|}{ Graduate or Above } \\
\hline & No. & $\%$ & No. & $\%$ & No. & $\%$ & No. & $\%$ & No. & $\%$ & No. & $\%$ \\
\hline Kurana & 38 & 058 & 149 & 2.28 & 711 & 10.91 & 124 & 1.90 & 22 & 0.33 & 24 & 0.36 \\
\hline Kalkheda & 212 & 3.25 & 53 & 0.81 & 267 & 4.09 & 136 & 2.08 & 117 & 1.79 & 25 & 0.38 \\
\hline Bagoniya & 223 & 3.42 & 156 & 2.39 & 698 & 10.71 & 222 & 3.40 & 168 & 2.57 & 13 & 0.19 \\
\hline Toomda & 232 & 3.56 & 22 & 0.33 & 582 & 8.93 & 872 & 13.38 & 38 & 0.58 & 21 & 0.32 \\
\hline Dhammarra & 544 & 8.34 & 36 & 0.55 & 167 & 2.56 & 386 & 5.92 & 249 & 3.82 & 9 & 0.13 \\
\hline TOTAL & 1249 & 19.16 & 416 & 6.38 & 2425 & 37.21 & 1740 & 26.70 & 594 & 9.11 & 92 & 1.41 \\
\hline
\end{tabular}

No. is number, \% is percentage.

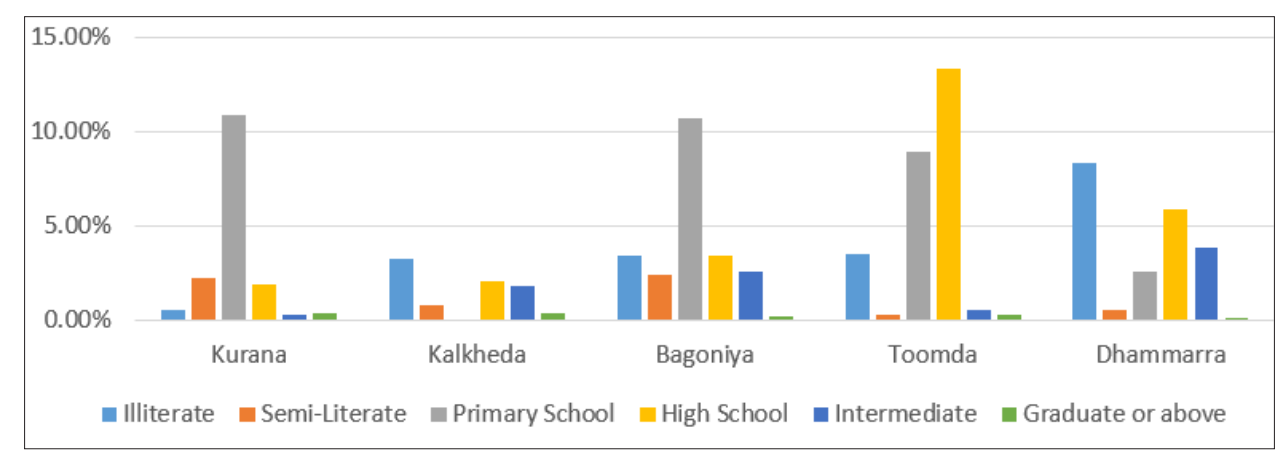

Figure 4.Education-wise Distribution of Population (\%)

Table 5.Occupation-wise Distribution of Population of the Five Villages of Bhopal district

\begin{tabular}{|c|c|c|c|c|c|c|c|c|c|c|c|c|c|c|c|c|}
\hline \multirow[t]{2}{*}{ Village } & \multicolumn{2}{|c|}{ None } & \multicolumn{2}{|c|}{ Landholder } & \multicolumn{2}{|c|}{$\begin{array}{l}\text { Agricu- } \\
\text { Itural } \\
\text { Labourer }\end{array}$} & \multicolumn{2}{|c|}{$\begin{array}{l}\text { Unskilled } \\
\text { Labourer }\end{array}$} & \multicolumn{2}{|c|}{$\begin{array}{l}\text { Skilled } \\
\text { Labourer }\end{array}$} & \multicolumn{2}{|c|}{ Business } & \multicolumn{2}{|c|}{ Student } & \multicolumn{2}{|c|}{ House wife } \\
\hline & No. & $\%$ & No. & $\%$ & No. & $\%$ & No. & $\%$ & No. & $\%$ & No. & $\%$ & No. & $\%$ & No. & $\%$ \\
\hline Kurana & 193 & 2.96 & 60 & 0.92 & 98 & 1.50 & 280 & 4.29 & 8 & 0.12 & 0 & 0 & 206 & 3.16 & 223 & 3.42 \\
\hline Kalkheda & 59 & 0.90 & 39 & 0.59 & 0 & 0 & 70 & 1.07 & 0 & 0 & 0 & 0 & 249 & 3.82 & 393 & 6.03 \\
\hline Bagoniya & 140 & 2.14 & 194 & 2.97 & 49 & 0.75 & 113 & 1.73 & 0 & 0 & 0 & 0 & 402 & 6.16 & 582 & 8.93 \\
\hline Toomda & 309 & 4.74 & 399 & 6.12 & 139 & 2.13 & 0 & 0 & 0 & 0 & 0 & 0 & 183 & 2.80 & 737 & 11.31 \\
\hline $\begin{array}{l}\text { Dham- } \\
\text { marra }\end{array}$ & 280 & 4.29 & 251 & 3.85 & 139 & 2.13 & 233 & 3.57 & 88 & 1.35 & 54 & 0.82 & 137 & 2.10 & 209 & 3.20 \\
\hline TOTAL & 981 & 15.05 & 943 & 14.47 & 425 & 6.52 & 696 & 10.68 & 96 & 1.4 & 54 & 0.82 & 1177 & 18.06 & 2144 & 32.90 \\
\hline
\end{tabular}

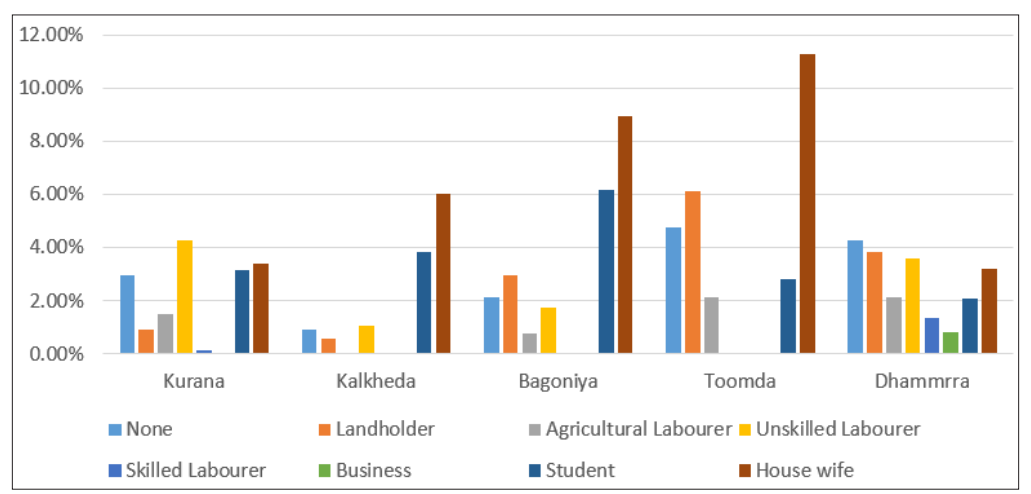

Figure 5.Occupation-wise Distribution of Population (\%) 
Table 6.Diet-wise Distribution of Population of the Five Villages of Bhopal district

\begin{tabular}{|c|c|c|c|c|c|c|}
\hline \multirow{2}{*}{ Village } & \multicolumn{2}{|c|}{ Vegetarian } & \multicolumn{2}{|c|}{ Non-vegetarian } & \multicolumn{2}{|c|}{ Vegetarian + Egg } \\
\hline & No. & $\%$ & No. & $\%$ & No. & $\%$ \\
\hline Kurana & 797 & 12.23 & 271 & 4.15 & 0 & 0.00 \\
\hline Kalkheda & 467 & 7.16 & 243 & 5.26 & 0 & 0.00 \\
\hline Bagoniya & 595 & 9.13 & 856 & 13.13 & 29 & 0.44 \\
\hline Toomda & 1644 & 25.23 & 123 & 1.88 & 0 & 0.00 \\
\hline Dhammarra & 1173 & 18.00 & 153 & 2.34 & 65 & 0.99 \\
\hline Total & 4676 & 71.76 & 1746 & 26.79 & 94 & 1.44 \\
\hline
\end{tabular}

No. is number, \% is percentage.

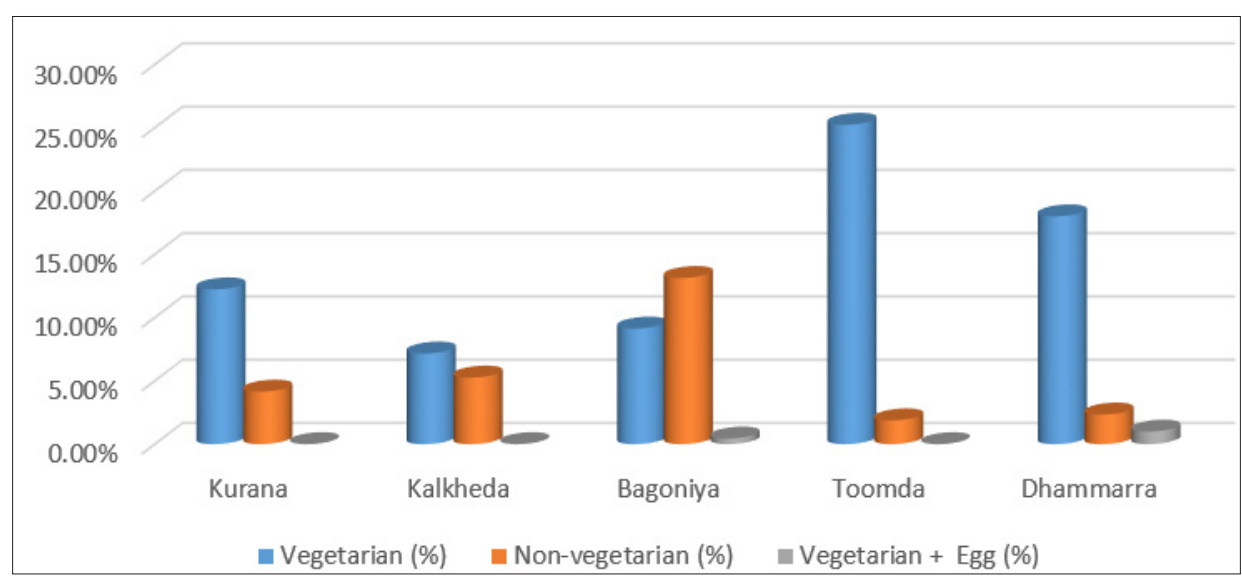

Figure 6.Diet-wise Distribution of Population (\%)

Table 7.Addiction-wise Distribution of Population of the Five Villages of Bhopal district

\begin{tabular}{|c|c|c|c|c|c|c|c|c|c|c|c|c|}
\hline \multirow{2}{*}{ Village } & \multicolumn{2}{|c|}{ None } & \multicolumn{2}{|c|}{ Tobacco } & \multicolumn{2}{|c|}{ Snuff } & \multicolumn{2}{|c|}{ Smoking } & \multicolumn{2}{|c|}{ Bhang } & \multicolumn{2}{|c|}{ Alcohol } \\
\hline & No. & $\%$ & No. & $\%$ & No. & $\%$ & No. & $\%$ & No. & $\%$ & No. & $\%$ \\
\hline Kurana & 1011 & 15.51 & 56 & 0.85 & 0 & 0.00 & 1 & 0.01 & 0 & 0 & 0 & 0 \\
\hline Kalkheda & 706 & 10.83 & 56 & 0.85 & 2 & 0.03 & 43 & 0.65 & 0 & 0 & 3 & 0.04 \\
\hline Bagoniya & 1384 & 21.24 & 80 & 1.22 & 0 & 0.00 & 9 & 0.13 & 0 & 0 & 7 & 0.10 \\
\hline Toomda & 1277 & 19.59 & 456 & 6.99 & 0 & 0.00 & 34 & 0.52 & 0 & 0 & 0 & 0 \\
\hline Dhammarra & 739 & 11.34 & 522 & 8.01 & 6 & 0.09 & 103 & 1.58 & 17 & 0.26 & 4 & 0.06 \\
\hline TOTAL & 5117 & 78.52 & 1170 & 17.95 & 8 & 0.12 & 190 & 2.91 & 17 & 0.26 & 14 & 0.21 \\
\hline
\end{tabular}

No. is number, \% is percentage.

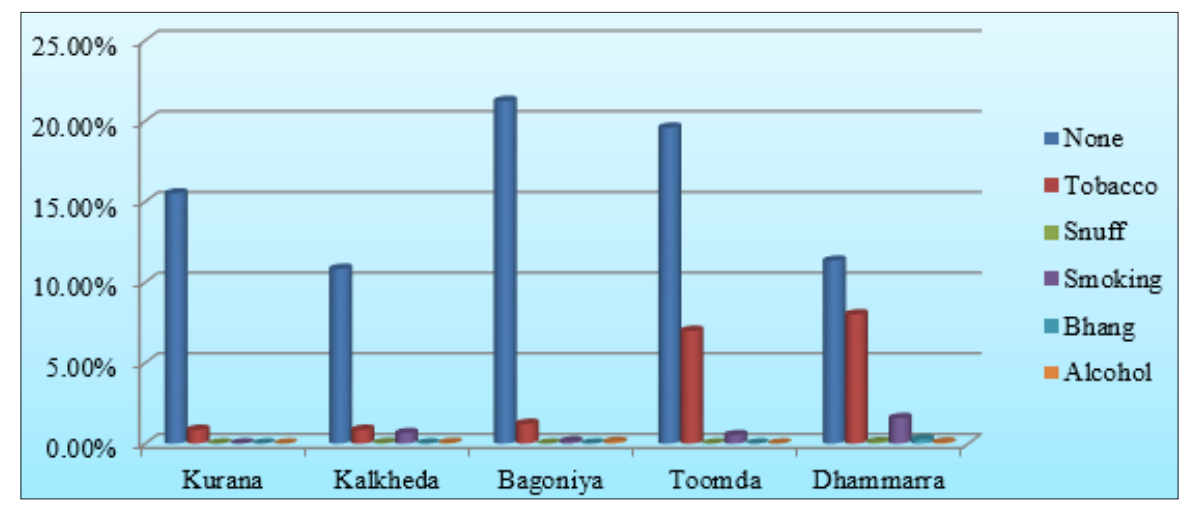

Figure 7.Addiction-wise Distribution of Population (\%) 
As shown in Table 7, majority (78.52\%) of the population had not given any history of addiction while $17.95 \%$ of the population were addicted to tobacco chewing, $2.91 \%$ population were addicted to smoking, $0.26 \%$ population were addicted to bhang, $0.21 \%$ population were addicted to alcohol, and $0.12 \%$ of population were addicted to snuff.

\section{Conclusion}

The collected and compiled data exhibit that the population that visited the OPDs belonged to SC population which is a low socio-economic group and is mainly dependent on agriculture and labour. The percentage of female population who visited the OPDs is more which reveals that due to the excessive burden of work and poor nutritional diet, they are more susceptible to have an illness. Tobacco addiction is found to be more prevalent than others. Moreover, poverty and scarcity of food have led to unsatisfactory dietary habit, albeit literacy is considerable in these villages.

\section{Source of Funding}

Central Council for Research in Unani Medicine

\section{Conflict of Interest: None}

\section{References}

1. Wikipedia, the free encyclopedia. [Internet]. Demographic analysis; c2020 [cited 2020 Dec 16]. Available from: https://en.wikipedia.org/wiki/ Demographic_analysis.

2. Lundquis JH, Anderton DL, Yaukey D. Demography The Study of Human Population. 4th ed. Waveland Press, Inc;2014 [Google Scholar]

3. Wikipedia, the free encyclopedia. [Interenet]. Socioeconomic status; c2020 [cited 2020 Dec 16]. Available from: https://en.wikipedia.org/wiki/ Socioeconomic_status\#: :text=Socioeconomic\%20 status\%20(SES)\%20is\%20a\%20n, position $\% 20 \mathrm{in} \% 20$ relation\%20to\%20others.

4. National Center for Educational Statistics. [Internet]. Glossary; 2008 [cited 2020 Dec 16]. Available from: https://nces.ed.gov/programs/coe/glossary.asp.

5. Wikipedia, the free encyclopedia. [Internet]. Socioeconomic statud; c2020 [cited 2020 Dec 16]. Available from: https://en.wikipedia.org/wiki/ Socioeconomic_status\#Health.

6. Adler NE, Boyce T, Chesney MA, Cohen S, Folkman S, Kahn RL, Syme SL. Socioeconomic Status and Health - The Challenge of the Gradient. Am Psychol. 1994;49(1):15-24. [PubMed] [Google Scholar]

7. Ahmed S, Rifaqat, Khan P, Ahmed S, Qayyum Z, Raheem A and Parveen S. A Socio Demographic Study of Rural Scheduled Castes of Aligarh, Uttar Pradesh, India. Hippocratic Journal of Unani Medicine. 2020;15(1):3342. 